\title{
Foraging strategy of masked boobies from the largest colony in the world: relationship to environmental conditions and fisheries
}

\author{
Henri Weimerskirch ${ }^{1, *}$, Matthieu Le Corre ${ }^{2}$, Charles A. Bost ${ }^{1}$ \\ ${ }^{1}$ Centre d'Etudes Biologiques de Chizé, CNRS, 79360 Villiers en Bois, France \\ ${ }^{2}$ Laboratoire d'Ecologie Marine, Université de la Réunion, 15 avenue René Cassin, BP 7151, 97715 Saint Denis, \\ Ile de la Réunion, France
}

\begin{abstract}
The largest masked booby Sula dactylatra colony in the world, with $>100000$ individuals, is located in the eastern tropical Pacific (ETP) on Clipperton Island. We studied their foraging ecology and their relationship with the environment as well as with the tuna purse seine fishery. We examined the movements of birds at sea and studied their diet. Breeding masked boobies foraged mainly during day time, departing early in the morning and returning late in the evening, with a few birds spending the night at sea mainly in flight. The foraging range of birds rearing chicks was on average $103 \mathrm{~km}$ (maximum $242 \mathrm{~km}$ ), with $73 \%$ of the time spent in flight. Foraging zones, as measured by first passage time analyses, indicated that zones of area-restricted search (ARS) were $3 \mathrm{~km}$ in diameter on average (average duration $1 \mathrm{~h}$ ) and were located at the extremity of individual trips. ARS zones were dispersed around Clipperton, with no particular concentration, and individual birds never returned to the same ARS from one trip to the next. These results suggest that the foraging sectors of masked boobies were unpredictable at a small scale. The foraging area was located in a zone of high primary production that had drifted from the coasts of Central America. This large-scale feature appears to be predictable and explains the strong seasonality in the breeding season of the population. This peak of productivity occurs year after year around the island in January to March, i.e. during the time of highest energy demand for the colony, when birds are feeding large chicks. Masked boobies dove at an average depth of $2 \mathrm{~m}$ (maximum $6 \mathrm{~m}$ ) and fed almost exclusively on flying fishes, with an estimated daily catch for the population of $69 \mathrm{t}$ of fish. Around Clipperton, yellowfin tuna are caught by the purse seine fishery in large numbers in association with dolphins. Since boobies are observed feeding almost exclusively in association with tuna and dolphins that drive flying fish to the surface, making them accessible for the birds, their dependence on tuna suggests that overexploitation of tuna stocks in this area could have a negative impact on the masked booby population.
\end{abstract}

KEY WORDS: Clipperton Island - Sula dactylatra - GPS · Eastern Tropical Pacific · Tuna fishery

\section{INTRODUCTION}

Flying seabirds are fast-moving marine predators that have developed specific searching strategies. Because reproduction occurs on land, the constraints imposed by the marine environment on seabird foraging are particularly strong during breeding, when they must commute between the colony and feeding grounds (Ashmole 1971). At this time, the proximity of prey aggregations to colonies or the ability of seabirds to forage efficiently and to reach distant prey patches at low energetic costs becomes critical. In temperate and polar regions, seabirds generally forage in areas where physical processes such as fronts, shelf edges or upwelling enhance productivity or passively concentrate prey (Wolanski \& Hamner 1988, Franck 1992, Hunt et al. 1999). These predictable zones concentrate top predators in large numbers. However, the predictability of the location of prey is dependent upon the spatial scale considered (Hunt \& Schneider 1987, 
Schneider 1993) and is generally high at a large or meso-scale (Hunt et al. 1999). At smaller scales, predators have to search actively for prey patches that can be sparsely and unpredictably spread. Top predators have therefore adopted specific foraging strategies to search optimally for prey at smaller scales.

In the open tropical oceans that represent almost half of the oceanic surface, production is overall low compared to temperate and polar waters (Longhurst \& Pauly 1987), and little information is available on seabird ecology. It is generally assumed that the distribution of prey patches for seabirds is more unpredictable than in colder waters (Ashmole 1971, Weimerskirch 2007). In these waters, rather than physical processes, biological processes appear to be of overwhelming importance for the feeding of tropical seabirds, in particular the association with sub-surface predators like tuna or dolphins (Au \& Pitman 1986, Ballance et al. 1997, Jaquemet et al. 2004). The Eastern Tropical Pacific (ETP) is an interesting zone with regards to tuna/dolphin and seabird associations because it is among the few areas where tuna occur close to the sea surface. The shallow thermocline in this area (Fiedler \& Talley 2006) is considered to be the main factor inducing the presence of large tuna and dolphins close to the surface. As a result, the largest purse seine tuna fishery in the world operates in this area, targeting yellowfin tuna (IATTC 2006). In the middle of the ETP, Clipperton Island is home to the largest colony of masked boobies Sula dactylatra in the world (Pitman et al. in press). Therefore, the presence of the tuna fishery in this area could have negative effects on boobies if the reduction in tuna stocks reduces feeding opportunities for seabirds (Ballance et al. 1997, Ballance \& Pitman 1999). In addition, the presence of this huge breeding population might have a significant impact on the marine resource surrounding the island, possibly resulting in an annulus where prey could be depleted (often referred to as 'Ashmole's halo', Ashmole 1963).

In this study, we investigated the foraging ecology of masked boobies from Clipperton Island during the peak of the breeding season using miniaturised data loggers allowing us to reconstitute the at-sea movements and behaviour of these tropical seabirds. The aims of the study were 3 -fold. First, we examined how individual birds forage in low productivity tropical waters and especially whether specific foraging adaptations appear. We were particularly interested in testing whether the low productivity and absence of strong physical processes may result in a specific way of foraging, and how this species deals with unpredictable prey patches. For example, if prey patches are unpredictable, individuals should not return repeatedly to the same area during successive trips (e.g. Hamer et al. 2001, Weimerskirch 2007), and at the population level, most individuals should not concentrate in specific areas. Second, we evaluated the impact of this large colony on the prey stocks, and the possible existence of an 'Ashmole's halo'. Third, we examined to what extent the fishery overlaps with the booby population and discuss possible effects of overexploitation of tuna on the masked booby population of Clipperton Island.

\section{MATERIALS AND METHODS}

The family Sulidae includes the gannets and boobies. While the 3 species of gannets are temperate or cold water foragers, boobies include 6 smaller species that breed at tropical latitudes (Nelson 1978). The masked booby is the largest tropical species (mass 1.5 to $2 \mathrm{~kg}$ ). Clutch size is typically 2 eggs, but after hatching, only 1 chick survives (Nelson 1978, author's pers. obs.).

The study was carried out on Clipperton Island $\left(10.3^{\circ} \mathrm{N}, 109.2^{\circ} \mathrm{W}\right)$ in the central eastern Pacific (Fig. 1) between 4 and 28 January 2005. Clipperton is a circular, closed coral atoll with a ring shape, roughly $3 \mathrm{~km}$ in diameter and 100 to $300 \mathrm{~m}$ wide. It is uninhabited and holds the largest masked boobies colony in the world ( 120 000 individuals, Pitman et al. in press). Masked boobies are seasonal breeders on Clipperton, with most egg-laying occurring in November (Pitman et al. in press). During our stay in January, birds were mainly rearing small to large chicks, with birds still incubating in $35 \%$ of nests (391 nests checked). Most of these incu-

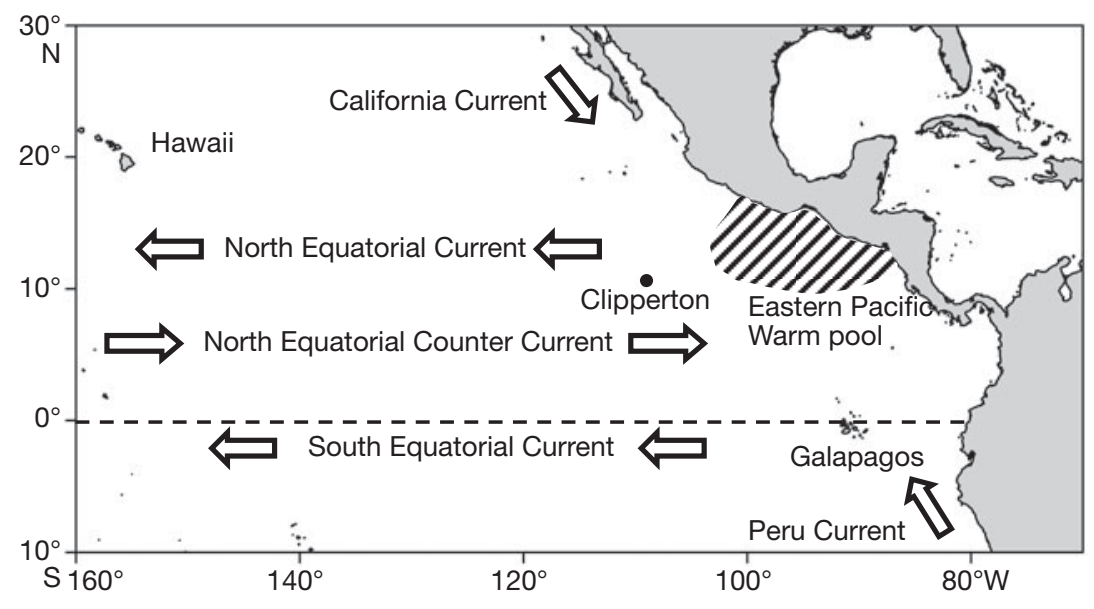

Fig. 1. Eastern Tropical Pacific, showing the location of Clipperton Island and the principal surface currents 
bating birds failed within the study period. At first capture, each bird was banded with a stainless steel band, measured (culmen length with a calliper, wing length with a ruler) and weighed in a bag using a Pesola balance. When recaptured for logger recovery, the birds were only weighed.

The main study plot included about 200 nests located on the western side of the atoll. At the beginning of the study period, a series of nests were randomly selected and marked with numbered plastic tags fixed in the soil with metal pegs, and the colony was mapped. On each nest, 1 bird of the pair was marked on the breast without handling using a sprayer; either with a yellow patch of picric acid or with blue animal marking paint. We could therefore identify birds rapidly and from a distance for monitoring nest attendance. The study colony was monitored 4 to 5 times per day (at dawn and dusk, i.e. at 06:00 and 17:45 h, and 2 to 3 times in the middle of the day) to check for the presence of adults on the nest and thus to infer the duration of foraging trips and departure and return of birds fitted with loggers. To attach the loggers or recover loggers after a foraging trip at sea, birds were captured with a fishing rod at night, either before dawn or after dusk.

To study the movements of boobies, we fitted 45 different individuals rearing chicks with a GPS receiver with integrated antenna and $1 \mathrm{MB}$ of flash memory, operated by a rechargeable battery (Newbehavior, Zurich, Switzerland; Steiner et al. 2000) and recording at $10 \mathrm{~s}$ intervals. The loggers were sealed into small polyethylene bags, and the overall weight of the device and its waterproof package was $32 \mathrm{~g}$ (1.5 to $2.2 \%$ of the body mass), i.e. below the generally accepted 3 to $5 \%$ threshold for adverse behavioural impacts (Croll et al. 1992, Phillips et al. 2003). Loggers were left on the birds for 1 to $2 \mathrm{~d}$ before being retrieved, giving a total of 62 foraging trips. To study diving behaviour, we fitted 18 individuals with time depth data loggers (M190-D2GT, 12 bit resolution, $60 \times 15 \mathrm{~mm}, 17 \mathrm{~g}$, Little Leonardo, Tokyo, Japan) recording depth every second. The relative accuracy for the depth sensor was $0.1 \mathrm{~m}$. In addition, 5 birds incubating eggs were fitted with GPS ( $\mathrm{n}=2$ ) or with an Argos satellite platform terminal transmitter (PTT; $\mathrm{n}=3$ birds, Microwave 100, $20 \mathrm{~g}$ ). All birds in the study plot on the western side of the atoll ring were fitted, except for 6 birds that were fitted with GPS on the opposite, eastern side of the atoll.

GPS, PTTs, and time depth recorders were taped under the 3 central tail feathers using Tesa ${ }^{\circledR}$ tape. Only 1 type of logger was fitted on each bird. GPS data were treated using a custom software package ('Diomedea', D. Filippi; see Weimerskirch et al. 2000, 2005 for details and other examples of its usage) to estimate time spent per sector. For GPS, satellites were lost during some sections of the trips, and therefore these sections were not considered in the analysis. The locations and duration of time spent on the water were derived from GPS data when flight speeds were $<10 \mathrm{~km} \mathrm{~h}^{-1}$ (Weimerskirch et al. 2005). For Argos transmitters, we only calculated the maximum range as the distance between the colony and the farthest location at sea for each trip.

To estimate the foraging areas of boobies we used 2 methods: (1) kernel estimation techniques to delineate the foraging ranges and the core habitat areas used by boobies and (2) the first passage time (FPT) method to estimate the size of the zones of area-restricted search (ARS). We used the fixed kernel method (Worton 1995) and the least square algorithm (Seaman \& Powell 1996). For estimations of surface foraged, we used the fixed kernel estimate of the $95 \%$ home range area (Seaman \& Powell 1996). For mapping purposes, we plotted the overall range and estimated contour levels for 50\% (core area) and $95 \%$ of the location distribution (Wood et al. 2000, Hyrenbach et al. 2002). The FPT method developed by Fauchald \& Tveraa (2003) to identify the spatial scale (measured through a circle of a given radius) at which an animal increases search effort was adapted for GPS data (Weimerskirch et al. 2007, Pinaud 2008). For each foraging trip, we estimated a destination bearing as the bearing between the colony and the first foraging patch, which is identified by a period when birds change direction continuously and reduce flight speed (see Weimerskirch et al. 2005), or the most distant point of a trip when no foraging patch was detected. To measure how consistent birds were in their destination, we tested the hypothesis that the directions of the first and second tracks were similar. For this purpose, we compared the data distribution to a random sampling $(n=1000)$ from a von Mises distribution. The von Mises distribution $M(\mu, \kappa)$ is a distribution for circular attributes (e.g. angles) with a mean direction $\mu$ and concentration parameter $\kappa$. For small $\kappa$, it tends toward a uniform distribution whereas for large $\kappa$, it tends toward a normal distribution with variance $1 / \kappa$ (i.e. circular normal distribution). We assumed that a value of $\kappa$ close to 0 corresponded to a uniform distribution (i.e. distinct bearing between successive trips). We then compared the difference in bearing with a Watson 2-sample test of homogeneity.

Sea surface chlorophyll concentrations and production data were derived from the SeaWiFS Local Area Coverage (LAC) ocean colour data and accessed through the site Bloomwatch 360 (http://coastwatch.pfel.noaa. gov/coastwatch/CWBrowserWW360.jsp), which provides estimates of chlorophyll and production on 0.025 and $0.1^{\circ}$ grids, respectively.

Masked boobies spontaneously regurgitate their stomach contents when handled, and food samples were collected from breeding adults $(n=27)$ caught at 
the nest while attending a chick or from chick regurgitates $(\mathrm{n}=4)$. Food samples were frozen and returned to our laboratory for analysis. In the laboratory, each sample was weighed; items were then separated from each other and weighed separately. Identification of prey was made using Smith \& Heemstra (1986) for fishes, Clarke (1986) and Nesis (1987) for squid, and our own reference collection. We measured fork length (FL, to the nearest $0.1 \mathrm{~mm}$ ), caudal length $(\mathrm{CL}$, to the nearest $0.1 \mathrm{~mm}$ ) and fresh mass $(\mathrm{M}$, to the nearest $0.1 \mathrm{~g}$ ) of all intact fish, and dorsal mantle length (ML, to the nearest $0.1 \mathrm{~mm}$ ), lower rostral length (LRL, to the nearest $0.01 \mathrm{~mm}$ ) and fresh mass (M) of all intact squids. We used allometric relationships (see Le Corre et al. 2003) to reconstitute mass and length of partially digested items of the 3 main groups of prey (the fish families Exocetidae and Hemiramphidae and the squid family Ommastrephidae).

Since no data exist on field and basal metabolic rate for the masked booby, we used information available on closely related species, i.e. the small $(0.9 \mathrm{~kg})$ red-footed booby (Ellis 1984, Ballance 1995) and the larger (3.2 kg) northern gannet (Birt-Friesen et al. 1989, Bryant \& Furness 1995) to calculate basal and field metabolic rates of masked boobies $(1.7 \mathrm{~kg})$, assuming a linear relationship between size and metabolic rates (Ellis \& Gabrielsen 2002). Assimilation efficiency was derived from Castro et al. (1989). Mean values are given $\pm 1 \mathrm{SD}$. All statistics were performed with Statistica 7.1.

\section{RESULTS}

Birds left the colonies mainly early in the morning; departure began just before dawn, and the duration of the trip was strongly constrained by the time of departure from the colony (Fig. 2a,b). The mean duration of foraging trips was $8.9 \pm 4.5 \mathrm{~h}$ (range 0.87 to $18.2 \mathrm{~h}$ ) and was related to the maximum foraging range attained (Fig. 3). Birds foraged at an average range of $103.1 \pm$ $65.6 \mathrm{~km}$ from the colony (range 5 to $245 \mathrm{~km}$ ). The distribution of trip duration showed 3 peaks, with a small proportion of trips of short duration (maximum 0.5 to $2 \mathrm{~h}$ ) and short range (8 to $24 \mathrm{~km}$ ), a large proportion of trips lasting 5 to $13 \mathrm{~h}$, with maximum foraging ranges between 50 and $142 \mathrm{~km}$ (median $107 \mathrm{~km}$ ), and a small proportion of longer trips (15 to $18 \mathrm{~h}$ ) with ranges of 215 to $242 \mathrm{~km}$ (Fig. 3). Foraging trips occurred mainly during the day, with a few longer trips during which significant time was spent at night (Fig. 2c). Time spent sitting on the water and especially diving occurred almost exclusively during the day, with 1 peak each in the morning and in the afternoon (Fig. 2d,e). The mean maximum range of birds fitted with Argos transmitters or GPS during incubation was $144.3 \pm 45.3$ km; no com-
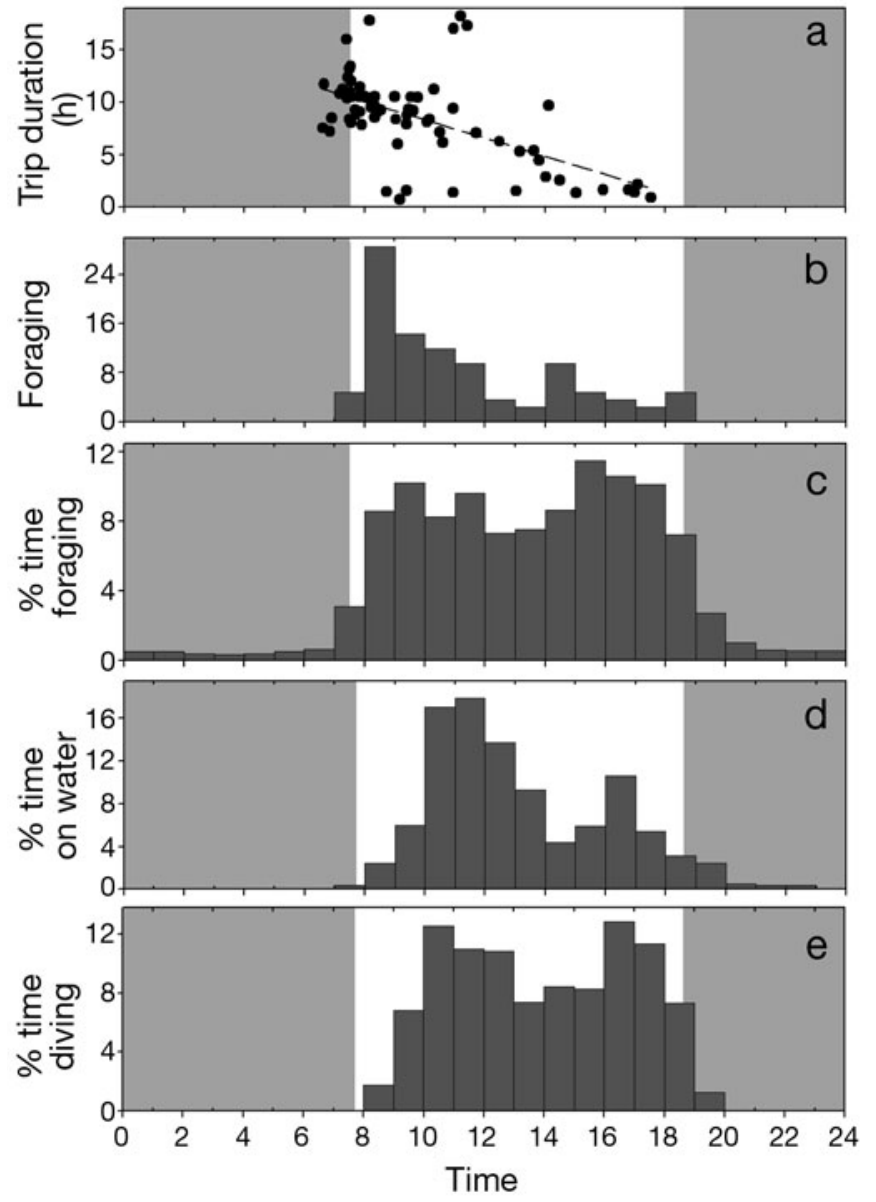

Fig. 2. Sula dactylatra. (a) Relationship between departure time and trip duration. Frequency distribution throughout the day of (b) departure time from the colony, and time spent (c) foraging, (d) at the water surface, and (e) diving. Grey shading indicates hours of darkness

parison between GPS and Argos data was made because of the different tracking systems.

From the time they left the colony to the time they returned to land, birds spent $78.1 \pm 14.3 \%$ (range 43.9 to $99.1 \%$ ) of the foraging time in flight, and the rest sitting on the water or diving. The median speed recorded by GPS for birds foraging at sea was $42 \mathrm{~km}$ $\mathrm{h}^{-1}$ with a maximum speed of $115 \mathrm{~km} \mathrm{~h}^{-1}$.

\section{Movements at sea}

When leaving the colony, birds generally take a particular bearing and keep a straight course before reaching a foraging zone where the flight speed decreases, with frequent changes in direction and more time spent on the water (Fig. 4). The return part of the trip is generally straight and parallel to the outgoing part. A few birds followed a more circular route, and there could be 

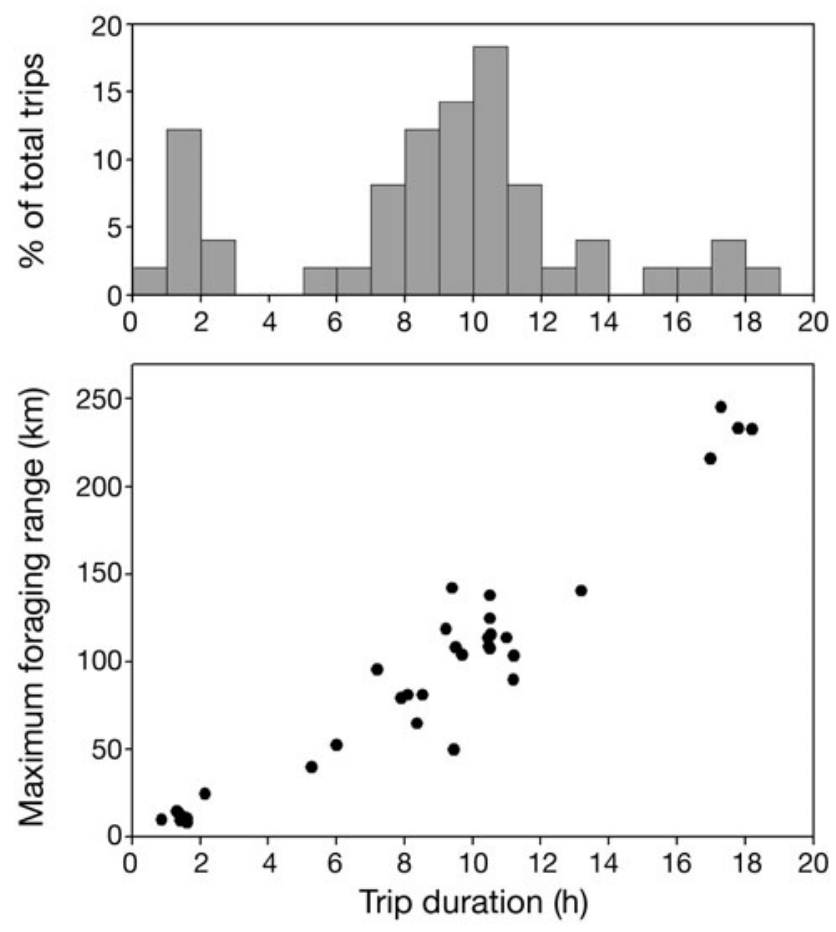

Fig. 3. Sula dactylatra. Frequency distribution of the duration of foraging trips, and relationship between trip duration and foraging range $\left(y=12.9 x-15.9, R^{2}=0.915, p<0.001\right)$

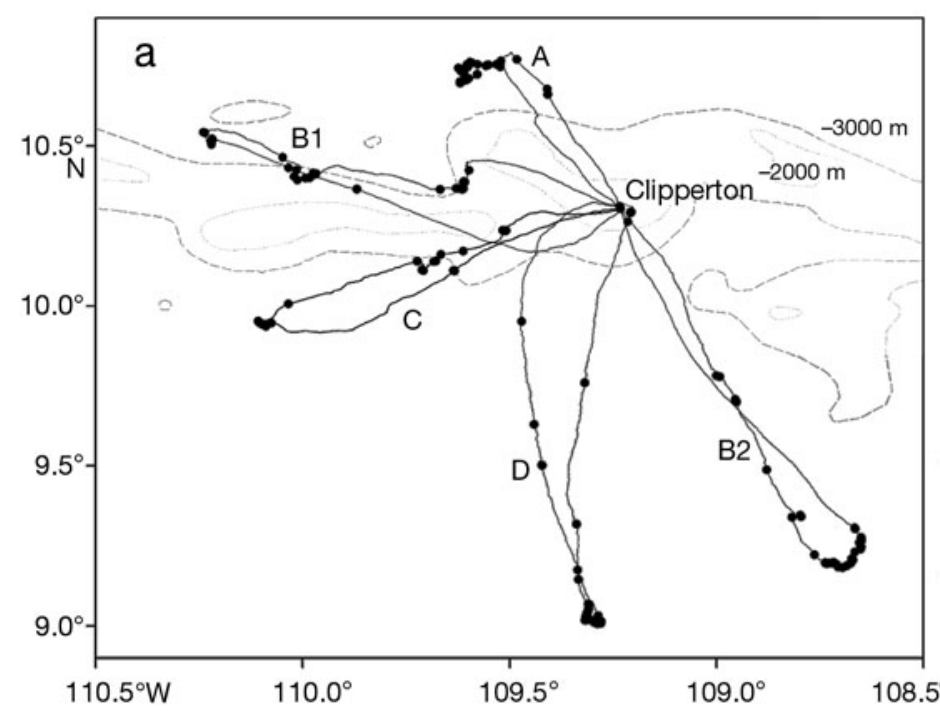

Fig. 4. Sula dactylatra. Foraging trips tracked by GPS recording at a frequency of 1 location every $10 \mathrm{~s}$. The black dots indicate when the speed was $<10 \mathrm{~km} \mathrm{~h}^{-1}$, i.e. when foraging activity (e.g. landing, diving) took place. (a) 5 long trips of 4 different individuals and (b) 4 successive short trips of the same individual one or several foraging zones during a trip. Although foraging activity took place at the most distant part of the foraging trip, FPT analysis indicated that zones of ARS were distributed evenly around the colony with no particular hotspot, because birds travelled different ranges (Fig. 5). The size of the ARS zone was on average $3.3 \pm 4.3 \mathrm{~km}$ (range 0.75 to $24 \mathrm{~km}$ ), and the average time spent in ARS was $1.1 \pm 1.2 \mathrm{~h}$.

The majority of trips were directed toward the southsouthwest, with few trips to the east or northeast (Fig. 6). Most birds departed from their colony on the western side of the atoll, but the 6 birds breeding on the eastern part of the atoll did not have different headings (Fig. $6, \chi^{2}{ }_{1}=0.28, p=0.598$ ). Wind blew mainly to the west-southwest throughout the study period (Fig. 6). Of 12 individuals tracked for at least 2 successive trips, none returned to the same foraging ARS zone from 1 trip to the next. Birds headed toward the same direction when leaving the colony in only $23 \%$ of the pairs of successive trips by the same individual (angular difference between successive flight direction $<30^{\circ}$ ). However, the difference in bearing angles (from the colony to the maximal distance) was not significantly different from a uniform distribution (comparison to a von Mises distribution, $\kappa=0.0001$, $\mathrm{U}^{2}=0.0589, \mathrm{p}>0.1$ ).

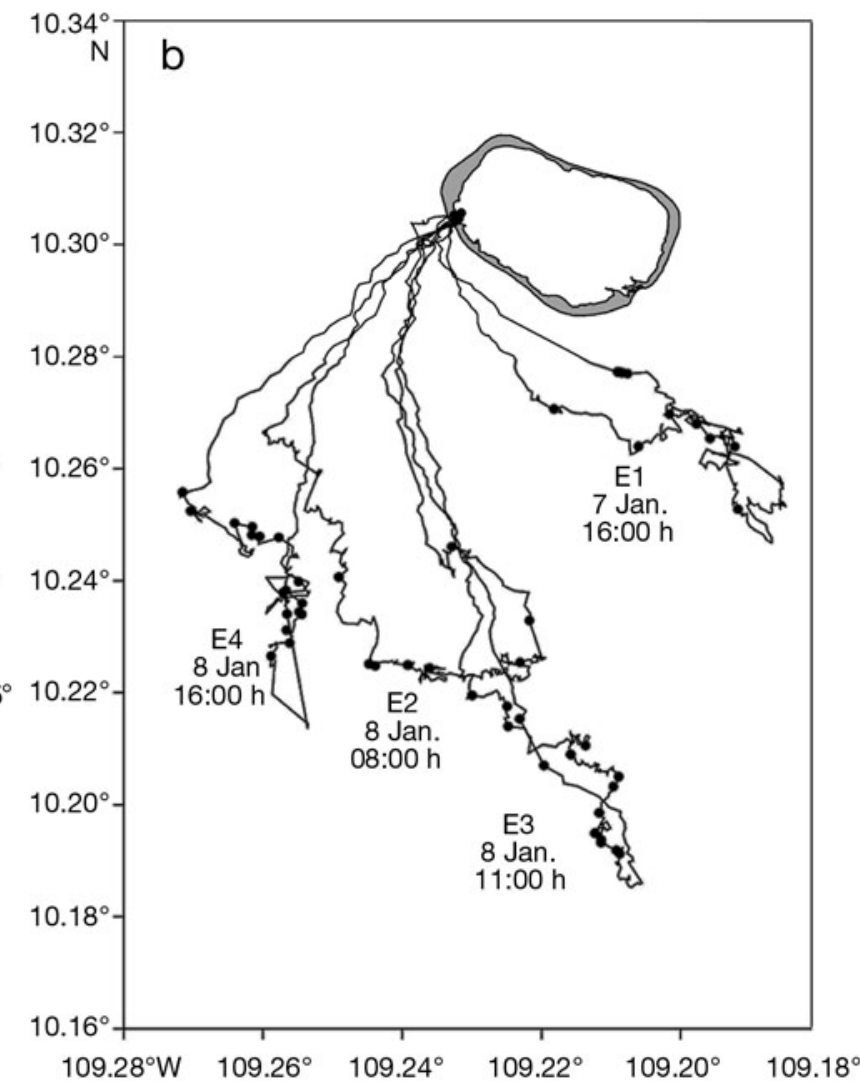



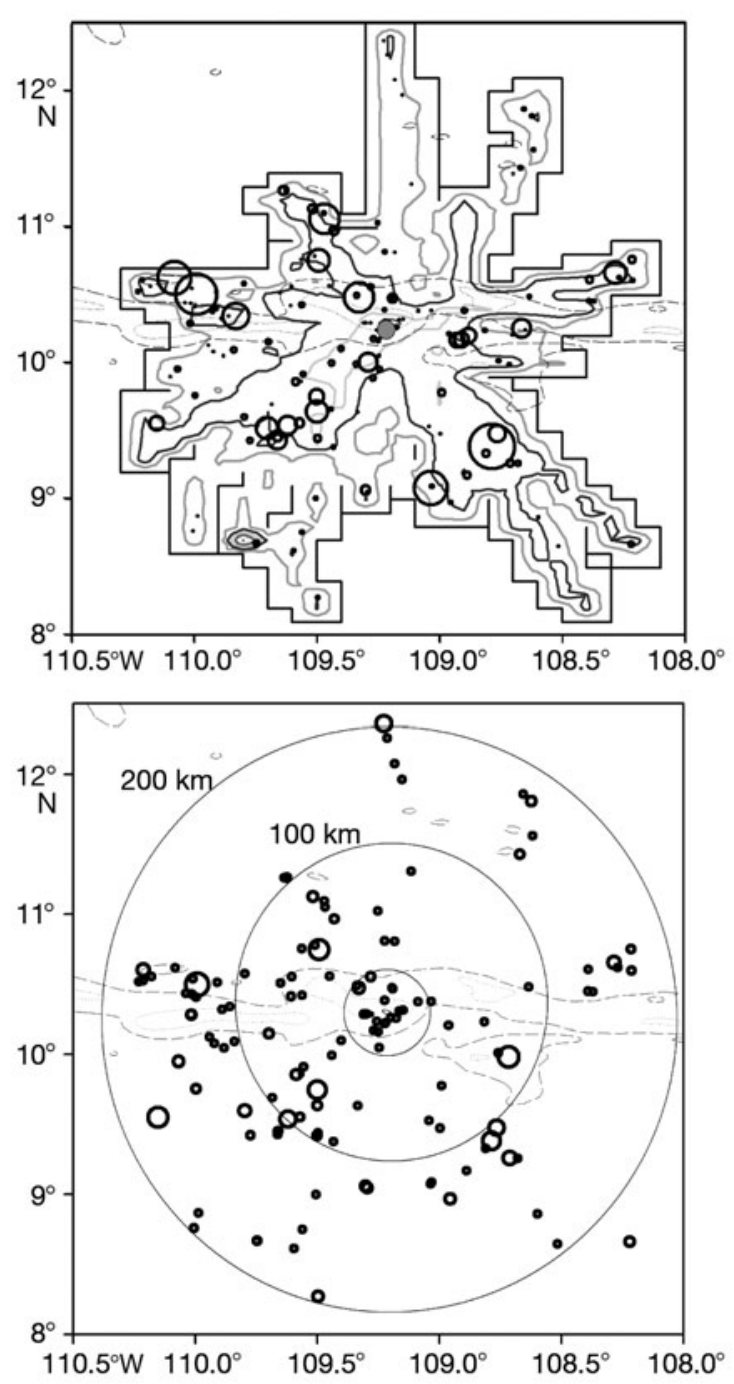

Fig. 5. Sula dactylatra. Clipperton sector showing (top) foraging zones as shown by density contour plots from kernel estimates of the amount of time spent at sea and ARS zones (circles, the size of the circle is proportionate to the size of ARS zone), and (bottom) distribution of ARS zones around Clipperton (the size of the circle is proportionate to the time spent foraging in the ARS zone). Concentric circles centred on Clipperton (grey circle) indicate 100 and $200 \mathrm{~km}$ distances

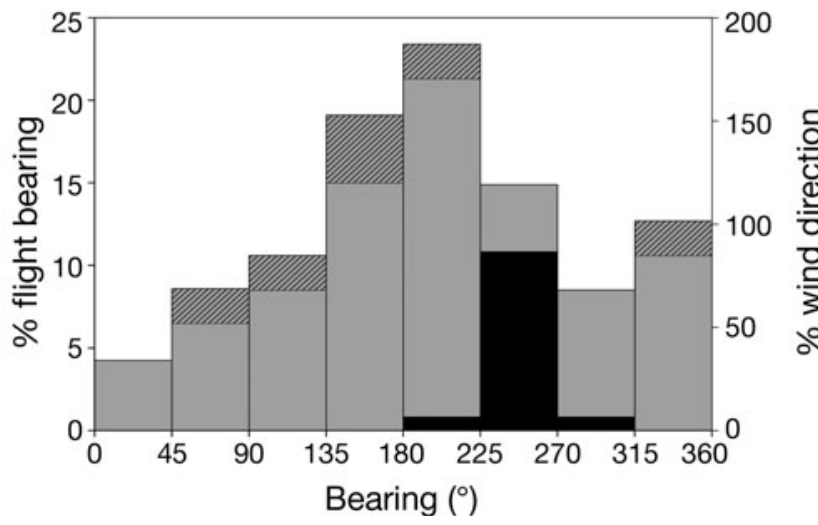

\section{Diving, diet and food requirement}

Birds dove at depths of $2.2 \pm 1.1 \mathrm{~m}$ on average (maximum $5.3 \mathrm{~m}, \mathrm{n}=1244$ dives) for short durations $(2.9 \pm$ $1.3 \mathrm{~s}$, maximum $10 \mathrm{~s})$. Masked boobies fed almost exclusively on fishes (98.6\% out of 212 prey items), especially flying fishes. By number, the prey caught were Exocetidae $(60.8 \%)$, Hemiramphidae $(27.3 \%)$, Coryphaenidae $(6.1 \%)$, other fish families (4.1\%) and ommastrephid squids (1.4\%). The mean mass of stomach contents was $206 \pm 90 \mathrm{~g}$, and the mean number of prey items per stomach content was $6.9 \pm 3.7$. Fish caught weighed $43.3 \pm 32.5 \mathrm{~g}$ with mean FL $=188 \pm$ $31 \mathrm{~mm}$ (maximum $278 \mathrm{~g}$ and $312 \mathrm{~mm}$ for a juvenile scombrid Auxis rochei).

Field metabolic rate of masked boobies is estimated to be $2300 \mathrm{~kJ} \mathrm{~d}^{-1}$, and basal metabolic rate is $600 \mathrm{~kJ} \mathrm{~d}^{-1}$ (see 'Materials and methods'). Since these birds feed almost exclusively on fish $\left(5.6 \mathrm{~kJ} \mathrm{~g}^{-1}\right)$ and have an assimilation efficiency of 0.744 , each adult requires an estimated $552 \mathrm{~g}$ of fish per day. During the study period, the food delivery rate to chicks was 300 g per chick. In January 2005, it was estimated that the population contained 115000 individuals (derived from Pitman et al. in press, authors' pers. obs.) in addition to 20000 chicks (pers. obs.). Thus, in January, the masked boobies of Clipperton were taking an estimated 63.2 (adults) +6.0 (chicks) $=69.2 \mathrm{t}$ of fishes daily.

\section{Oceanographic conditions, production and fishery distribution}

The study area of the ETP is a zone of deep waters, with a narrow ridge where Clipperton is located. Deep waters are therefore very close offshore from Clipperton, and there is no peri-insular shelf (Fig. 5). The productivity for these oceanic waters as derived from chlorophyll concentration and primary production measures was overall low (average $0.2 \mathrm{mg}$ chlorophyll $\mathrm{m}^{-3}$ ), with a certain heterogeneity in distribution (Fig. 7a). During the course of the study, the oceanographic conditions did not change extensively, with a slow westward movement of a zone of higher productivity ( $>0.32 \mathrm{mg}$ chlorophyll $\mathrm{m}^{-3}$ ) originating from the

Fig. 6. Sula dactylatra. Frequency distribution of foraging trip departure directions (grey bars) and of the direction toward which wind was blowing (black columns). The hatched sections of the bars correspond to the directions taken by birds from a colony located at the eastern end of the atoll; the rest of birds departed from the western end of the atoll 
a

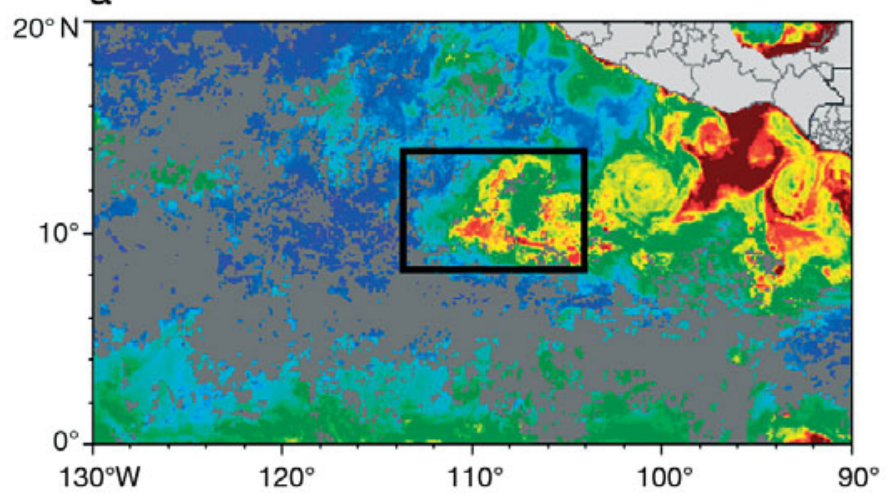

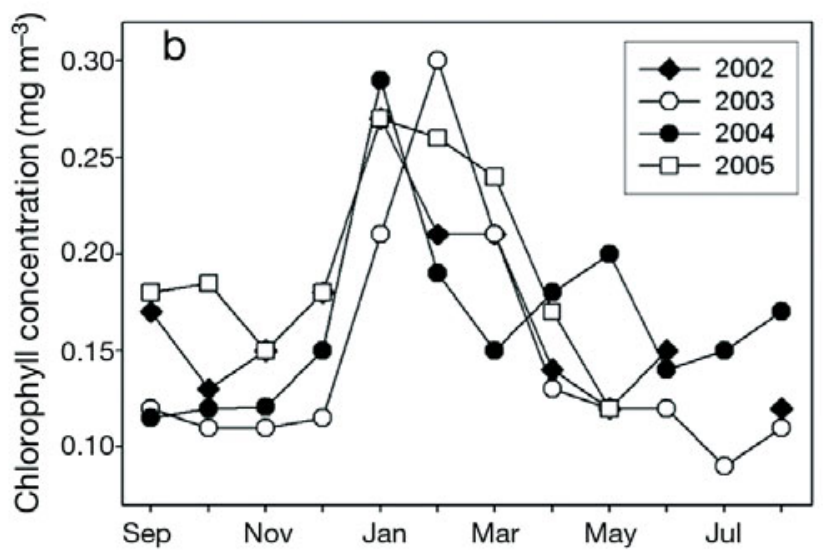

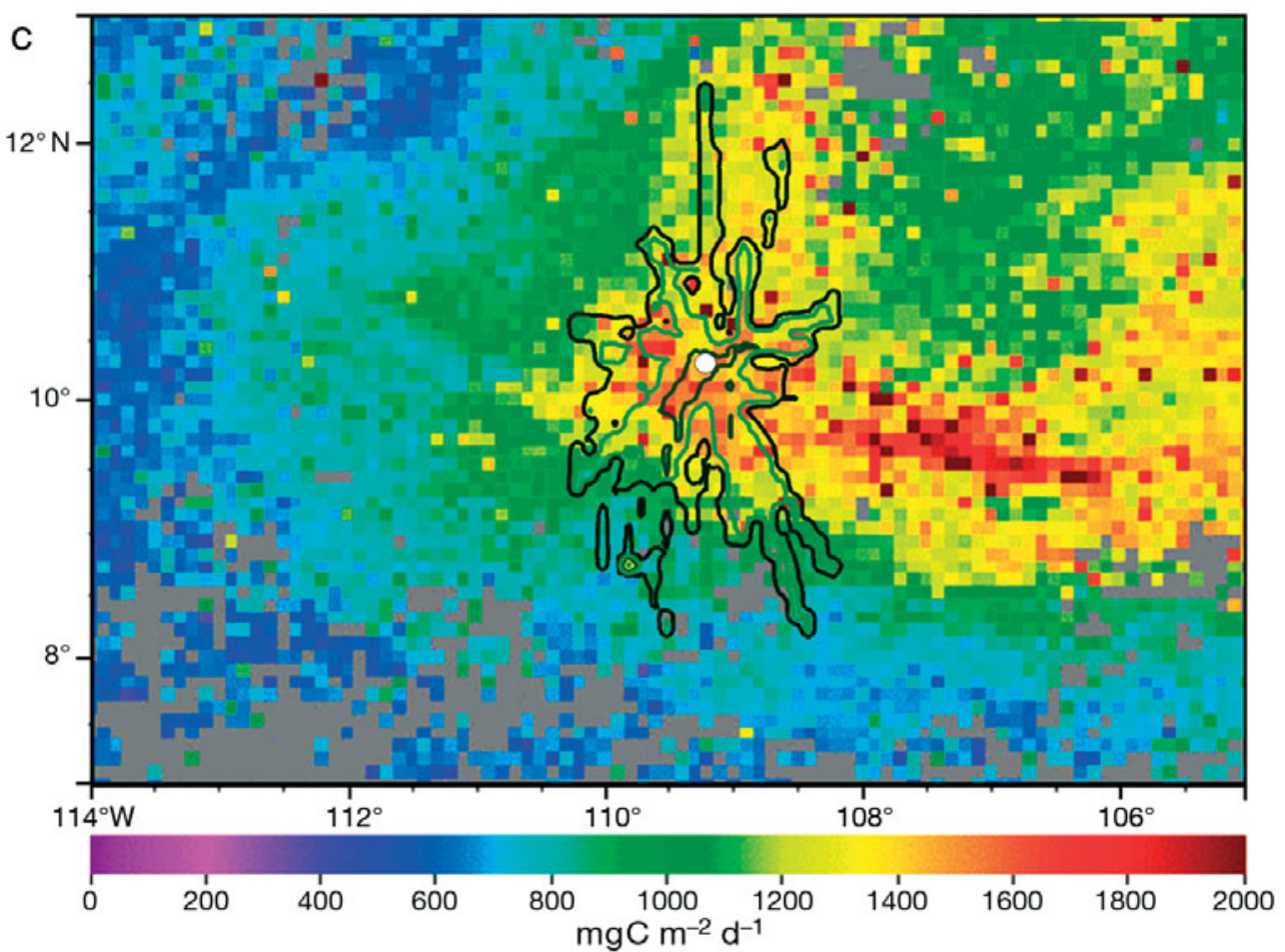

Fig. 7. Sula dactylatra. (a) ETP sector showing primary productivity (from NASA, Aqua MODIS and Pathfinder satellite data), (b) the changes over the year in chlorophyll concentrations around Clipperton averaged in the box in map (a) over 4 successive years and (c) enlargement of the box in map (a) showing the primary productivity around Clipperton and the kernel distribution of foraging by masked boobies

Gulf of Tehuantepec transported westward by the North Equatorial current (Fig. 7a). The increased productivity of the Clipperton area appears to be a seasonal feature, with peaks of productivity generally attained in January to March each year (Willett et al. 2006; Fig. 7b) during the chick-rearing period of masked boobies. During the study period in January, the finer scale map shows that productivity was relatively high in the foraging zone of masked boobies $\left(1.3 \pm 0.4 \mathrm{gC} \mathrm{m}^{-2} \mathrm{~d}^{-1}\right)$, but not significantly different from the other zones not visited within the $245 \mathrm{~km}$ foraging range of the population $(1.2 \pm 0.8, U$-test, $Z=1.2, \mathrm{p}=0.210 ;$ Fig. $7 \mathrm{c}$ ).
The tuna fishery operating in the Clipperton sector has fished throughout the year during recent years, including 2005 and 2006. Catches in the area are primarily yellowfin tuna, which are caught mainly in association with dolphins. Fish-aggregating devices (FADs) are used to the south of Clipperton outside the range of the breeding booby population. In January 2005, the purse seine fishery operating in the Clipperton sector overlapped little with the breeding population of masked boobies (Fig. 8a). However, when considering the entire year, high catches of yellowfin tuna associated with dolphins were reported within the range of Clipperton boobies (Fig. 8b, IATTC 2006). 

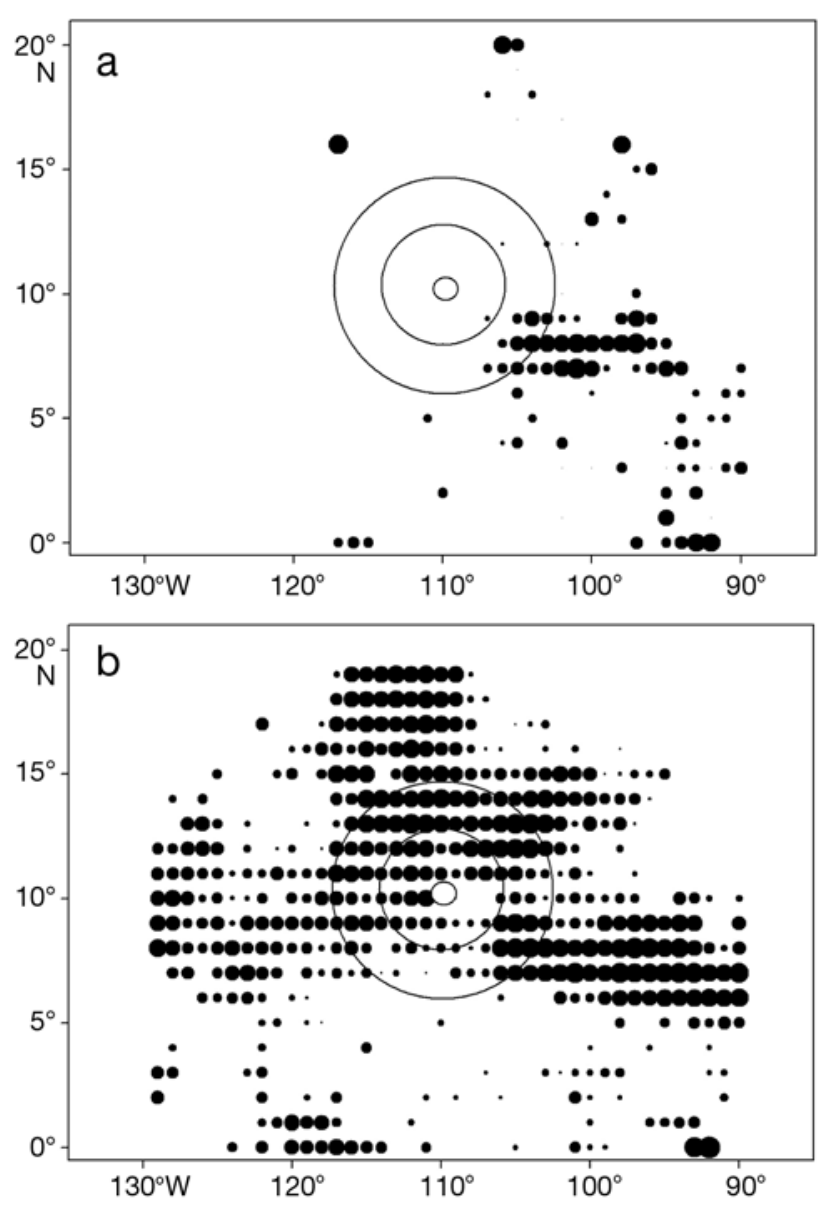

Fig. 8. Sula dactylatra. (a) Clipperton area showing the distribution of tuna captures during January 2005, all species and set types combined. (b) Clipperton sector showing the capture of tuna for sets associated with dolphins, October 2004 to September 2005 (i.e. for the masked booby breeding season 2004-2005). Black circles are log (total captures per $1^{\circ} \times 1^{\circ}$ square) (IATTC 2006). Concentric circles indicate 200 and $400 \mathrm{~km}$ distances from Clipperton (central circle)

\section{DISCUSSION}

\section{Foraging range and strategy}

Clipperton masked boobies rearing chicks appear to be pelagic, with a maximum foraging range of $245 \mathrm{~km}$. The average range is $103 \mathrm{~km}$ and is limited by the fact that birds forage mainly during the day and only a small proportion is at sea during the night, mainly commuting. Very little time is spent on the sea surface at night, in contrast to gannets that spend considerable time at the sea surface when at sea at night (Hamer et al. 2001). Thus, like red-footed boobies (Weimerskirch et al. 2005, 2006) masked boobies appear to avoid spending time at sea at night, especially sitting on the water, possibly to avoid predation by sharks. As a con- sequence of this behaviour, their foraging range is limited. The timing of departure from the colony appears to be the major factor explaining the duration of foraging bouts, and therefore range, in this population, suggesting strong constraints on foraging time (Lewis et al. 2004). Consequently, most birds leave the colony early in the morning to have the longest period of daytime for foraging, and therefore the longest foraging range. Another reason why masked boobies might be mostly diurnal foragers is that both yellowfin tuna and dolphins, with whom birds associate to feed in the ETP (Au and Pitman 1986), are diurnal feeders (Perrin et al. 1973). With an average flight speed of $40 \mathrm{~km} \mathrm{~h}^{-1}$, a $12 \mathrm{~h}$ return flight gives a potential maximum range of $240 \mathrm{~km}$ if they forage only during the day and fly continuously in a straight line. Because birds spend a significant part of the foraging trip on the water, or making ARS, the maximum range by day time is $150 \mathrm{~km}$. However, some birds are able to extend their range to $245 \mathrm{~km}$ by spending a significant part of the trip travelling at night, mainly during the return phase of the trip.

At the Galapagos Islands, breeding masked boobies have an estimated foraging range of $65 \mathrm{~km}$ from the colony (Anderson \& Ricklefs 1987). Red-footed boobies from Europa Island forage at an average distance of $67 \mathrm{~km}$ (maximum $148 \mathrm{~km}$, Weimerskirch et al. 2005), i.e. a shorter range than masked boobies, even though red-footed boobies are considered the most pelagic of all boobies (Nelson 1978). Thus, masked boobies from Clipperton, despite their apparent reluctance to spend the night at sea, and especially to sit on the water at night, appear to have a long foraging range compared to other tropical species. The larger gannets Morus bassanus forage at maximum ranges of $540 \mathrm{~km}$ (mean $232 \mathrm{~km}$ ) for trips lasting 13 to $84 \mathrm{~h}$ (Hamer et al. 2000), and cape gannets $M$. capensis forage at maximum distances of $242 \mathrm{~km}$ (mean $85 \mathrm{~km}$ ) for trips lasting 1.5 to $48 \mathrm{~h}$ (Grémillet et al. 2004). Range in the larger temperate species seems to be extended only by their ability to spend the night at sea. In the Mozambique Channel, a study on non-breeding masked boobies indicates a range up to $350 \mathrm{~km}$ with a duration of foraging of up to $4.5 \mathrm{~d}$ (Asseid et al. 2006), suggesting that breeding is also a strong constraint for foraging range and time.

The foraging strategy of masked boobies is to leave the colony rapidly with a particular bearing and to keep their bearing until they reach a zone where they perform an ARS. In pelagic seabirds, ARS seems to be a common strategy (Veit \& Prince 1997, Nevitt \& Veit 1999). The hypothesis is that, once a bird has detected prey, it changes its flight route from a straight-line route to a series of changes in direction. During the study period, masked boobies foraged in all directions from Clipperton, but with higher densities to the southwest. The overall foraging zone overlap was distrib- 
uted over relatively productive waters in the ETP, and productivity was not higher to the southwest, or within the actual total range of the population, than within the rest of the potential range (radius of $240 \mathrm{~km}$ ). Flight directions at departure could also be influenced by the prevailing wind, although the general heading is not directly in the wind trace. Another factor that may influence foraging zone preference is the existence of a hinterland model, whereby neighbouring colonies occupy non-overlapping feeding zones at sea (Cairns 1989). Thus, birds originating from different colonies may take different bearings (e.g. Weimerskirch et al. 1988, Grémillet et al. 2004), and this could explain why birds breeding on the western side of the atoll head toward the southwest. However, although our sample size is limited, birds breeding on the eastern side did not have different bearings from those breeding on the western side.

Successive trips by the same bird indicate that individuals do not return to the same foraging area in subsequent trips, suggesting that, at a small scale, prey patch locations are not predictable. In the Galapagos, masked boobies appear to change flight direction from one day to the next, also suggesting that prey location was not predictable (Anderson \& Ricklefs 1987). In temperate and polar waters, in contrast, many species return to the same areas from one foraging trip to the next (see review by Hunt et al. 1999, Weimerskirch 2007). Hamer et al. (2001) found very similar bearings and distances travelled in successive foraging trips of temperate northern gannets in the North Sea, suggesting predictable locations in prey patches for this area. Cape gannets concentrate their foraging effort in upwelling zones in the Benguela Current (Grémillet et al. 2004). However, the flight directions recorded in studies in temperate zones are influenced by the presence of continental masses. Nevertheless, other studies on oceanic islands suggest that fidelity to feeding sites occurs in temperate and polar zones (e.g. Weimerskirch 2007). Conversely, the flight directions of masked boobies in the Mozambique Channel, where birds foraged from an island along the coast of Africa, seem to indicate that birds fly successively in different directions (Asseid et al. 2006), but more data are necessary. These results are consistent with the idea that tropical marine habitats are less predictable than temperate habitats for seabirds (Weimerskirch 2007).

At a fine scale (kilometres to hundreds of metres), the distribution of ARS indicates that numerous feeding opportunities are scattered in the vicinity of Clipperton and are not concentrated in particular zones. Tropical seabirds are dependent on the activity of subsurface predators that make small fishes and squid available for birds at the surface (Au \& Pitman 1986). This is particularly the case in the ETP, where the shal- low thermocline is responsible for the presence of tuna close to the surface (Ballance et al. 2006), and observations at sea show that masked boobies rely almost exclusively on associations with tuna and dolphins for feeding (Au \& Pitman 1986, Ballance et al. 1997, Ballance \& Pitman 1999). The absence of predictability in prey distribution explains why birds do not return to the same area between trips, but rather may be searching for schools of tuna and dolphins that are very mobile, but probably present in large numbers within the foraging range of the colony.

\section{Oceanographic conditions and seasonality of breeding}

In the ETP, Ballance et al. (1997) found that boobies occurred only in the vicinity of breeding grounds located in the eastern part of their study plot. Those authors attributed this to the higher productivity of waters in this area $\left(0.17 \mathrm{mg}\right.$ chlorophyll $\left.\mathrm{m}^{-3}\right)$, rather than to the proximity of breeding grounds. In the ETP, productivity increases progressively when moving eastward. In the Gulf of Tehuantepec, on the eastern coastal side of the eastern tropical warm pool, productivity is extremely high due to wind-driven upwelling along the coast of Central America (Pennington et al. 2006). From each autumn until early spring, production is then moved westward with eddies that are formed off the coastal region (Willett et al. 2006). Such eddies transport production to the open ocean, and in January 2005, during the course of our study, a zone of high production occurred near Clipperton (Fig. 7). This process occurs every year (Willett et al. 2006) in January to March (Fig. 7b), at the peak of the chick-rearing period, i.e. when food demand is at the highest in the colony of masked boobies. Like many other tropical seabirds, breeding of masked boobies is generally not synchronised, and laying can occur throughout the year (Nelson 1978). At Clipperton, the relative synchrony in breeding, with the peak of laying occurring every year in November, is probably an adaptation to the predictability of the peak of production at the time of chick-rearing in January to March. Similarly, the fishing season appears to occur mainly during the first part of the year (IATTC 2006).

\section{Impact of the population on the marine environment}

Clipperton Island is home to the largest masked booby colony in the world (Pitman et al. in press). The impact of these seabirds around the colony is significant, with an estimated minimum of $69 \mathrm{t}$ of fish caught every day within a radius of $200 \mathrm{~km}$ around the island. 
During the study period, masked boobies fed mainly on flying fishes and flying squid, i.e. similar prey to that in other localities (Nelson 1978, Harrison et al. 1983, Schreiber et al. 1996). The long foraging range of Clipperton masked boobies, compared to other booby populations, may be a result of the high energetic requirement of the large population. Indeed, it is generally considered that intraspecific competition leads to longer foraging ranges (Lewis et al. 2001). Ashmole (1963) suggested that, because of intraspecific competition, birds may be foraging farther, leading to an annulus of foraging zone far from the colony, because of prey depletion close to the colony. There was no tendency for ARS zones to be located only far from the colony; rather, feeding opportunities were distributed evenly around the island. This may be due to the fact, that in the case of masked boobies, patchy prey resources are continuously moving with schools of tuna and dolphins that are very mobile. Foraging range may be extended because of direct intraspecific interference competition, but not because of prey depletion close to the colony. The study was carried out during the chick-rearing period when constraints are the highest, because a chick must be fed regularly while being guarded by an adult. During incubation, birds probably forage farther from the island, and nonbreeding birds could probably forage even farther (see preliminary results of Asseid et al. 2006). Thus, competition should be highest during the chick-rearing period, and this could explain why in this tropical species with a large population there has been selection for a seasonal breeding at the peak of production around the island.

\section{Impact of fishery}

Clipperton is located in the centre of the world's largest surface fishery for yellowfin tuna (IATTC 2006). In the Clipperton area, yellowfin tuna are caught in association with dolphins. Yellowfin tuna are the main tuna fished by the purse seine fishery, and are found close to the surface likely because of the shallow thermocline of the sector. They prey on a variety of epipelagic fishes, including flying fishes, which are a minor prey item for them (Perrin et al. 1973) but constitute the bulk of the prey for boobies. Conversely, dolphins that are associated with tuna do not feed on flying fishes (Perrin et al. 1973), indicating that the association between seabirds, tuna and dolphin is complex, since dolphins are generally considered to stay closer to the surface than tuna, partly because of their need to breathe frequently (e.g. Edwards 1992).

The obligatory association of boobies with tuna in the ETP suggests that overfishing may have a negative impact on the booby population. If schools of tuna become less abundant following overexploitation, feeding opportunities will become less frequent, resulting in longer foraging ranges or longer time spent foraging, thereby reducing breeding success. The potential impact of this fishery seems especially relevant today, since the growth rate of this large colony, which has been recovering from predation on land by humans and introduced pigs, is probably approaching an asymptote (Pitman et al. in press) at the same time that the purse seine fishery is attaining record values (IATTC 2006). In 2005, the catch rates for yellowfin were lower than average, and fish caught were of smaller size (IATTC 2006), suggesting that the fishery could already be overexploiting the yellowfin stocks. The monitoring of foraging behaviour and size of the population on an island such as Clipperton would provide a very convenient indicator of the state of the ecosystem in the ETP zone.

Acknowledgements. We profoundly thank Dr. Jean Louis Etienne who organised the expeditions on Clipperton Island for the logistical and financial support of the study, and Conseil Régional Poitou Charentes, Université de la Réunion, for additional financial support. We thank all participants of the expedition who helped us during the field work. We thank Yann Ropert Coudert and Akiko Kato for providing timedepth recorders, David Pinaud and Hélène Gadenne for help with the data processing, and Michael Hinton and IATTC for giving us access to public domain data on the distribution of fishing catches in the Clipperton area. We thank Antoine Hauselman for his help during the food sample analysis, Cédric Cotté for help with statistical analysis and Lisa Ballance and 3 anonymous referees for helpful comments on the manuscript.

\section{LITERATURE CITED}

Anderson DJ, Ricklefs RE (1987) Radio-tracking Masked and Blue-footed Boobies (Sula spp.) in the Galàpagos Islands. Natl Geogr Res 3:152-163

Ashmole NP (1963) The regulation of numbers of tropical oceanic birds. Ibis 103:458-473

Ashmole NP (1971) Seabird ecology and the marine environment. In: Farner DS, King JR (eds) Avian biology, Vol 1. Academic Press, New York, p 223-286

Asseid BS, Drapeau L, Crawford RJM, Dyer BM and others (2006) The food of three seabirds at Latham Island, Tanzania, with observations on foraging by masked boobies Sula dactylatra. Afr J Mar Sci 28:109-114

Au DWK, Pitman RL (1986) Seabird interactions with dolphins and tuna in the eastern tropical Pacific. Condor 88: 304-317

Ballance LT (1995) Flight energetics of free-ranging redfooted boobies (Sula sula). Physiol Zool 68:887-914

Ballance LT, Pitman RL (1999) Foraging ecology of tropical seabirds. In: Adams NJ, Slotow RH (eds) Proc 22nd Int Ornithol Congr, Durban. Birdlife South Africa, Johannesburg, p 2057-2071

Ballance LT, Pitman RL, Reilly SB (1997) Seabird community structure along a productivity gradient: importance of competition and energetic constraint. Ecology 78:1502-1518 
Ballance LT, Pitman RL, Fiedler FC (2006) Oceanographic influences on seabirds and cetaceans of the eastern tropical Pacific: a review. Prog Oceanogr 69:360-390

Birt-Friesen VL, Montevecchi WA, Cairns DK, Macko SA (1989) Activity-specific metabolic rates of free-living northern gannets and other seabirds. Ecology 70:357-367

Bryant DM, Furness RW (1995) Basal metabolic rates of north Atlantic seabirds. Ibis 137:219-226

Cairns DK (1989) The regulation of seabird colony size: a hinterland model. Am Nat 134:141-146

> Castro G, Stoyan N, Myers JP (1989) Assimilation efficiency in birds: a function of taxon or food type? Comp Biochem Physiol A 92:271-278

Clarke MR (1986) A handbook for the identification of cephalopod beaks. Clarendon Press, Oxford

$>$ Croll DA, Gaston AJ, Burger AE, Konof D (1992) Foraging behavior and physiological adaptations for diving in thickbilled murres. Ecology 73:344-356

Edwards EF (1992) Energetics of associated tunas and dolphins in the eastern tropical Pacific Ocean: a basis for the bond. Fish Bull 90:678-690

Ellis HI (1984) Energetics of free-ranging seabirds. In: Whittow GC, Rahan H (eds) Seabird energetics. Plenum Press, New York, p 203-234

Ellis HI, Gabrielsen GW (2002) Energetics of free-ranging seabirds. In: Schreiber EA, Burger J (eds) Biology of marine birds. CRC Press, Boca Raton, FL, p 359-407

Fauchald P, Tveraa T (2003) Using First-Passage Time in the analysis of area-restricted search and habitat selection. Ecology 84:282-288

Fiedler PC, Talley LD (2006) Hydrography of the eastern tropical Pacific: a review. Prog Oceanogr 69:143-180

Franck PJS (1992) Phytoplankton blooms at fronts: patterns, scales and physical forcing mechanisms. Rev Aquat Sci 6: 121-137

Grémillet D, Dell'Omo G, Ryan PG, Peters G, Ropert-Coudert Y, Weeks SJ (2004) Offshore diplomacy, or how seabirds mitigate intra-specific competition: a case study based on GPS tracking of cape gannets from neighbouring colonies. Mar Ecol Prog Ser 268:265-279

Hamer KC, Phillips RA, Wanless S, Harris MP, Wood AG (2000) Foraging ranges, diets and feeding locations of gannets Morus bassanus in the North Sea: evidence from satellite telemetry. Mar Ecol Prog Ser 200:257-264

Hamer KC, Phillips RA, Hill JK, Wanless S, Wood AG (2001) Contrasting foraging strategies of gannets Morus bassana at two North Atlantic colonies: foraging trip duration and foraging area fidelity. Mar Ecol Prog Ser 224:283-290

Harrison CS, Hida TS, Seki MP (1983) Hawaiian seabird feeding ecology. Wildl Monogr 85:1-71

Hunt GL Jr, Schneider DC (1987) Scale dependent processes in the physical and biological environment of marine birds. In: Croxall JP (ed) Seabirds: feeding biology and role in marine ecosystems. Cambridge University Press, Cambridge, $\mathrm{p}$ 7-41

Hunt GL, Mehlum F, Russell RW, Irons D, Decker MB, Becker PH (1999) Physical processes, prey abundance, and the foraging ecology of seabirds. In: Adams NJ, Slotow RH (eds) Proc 22nd Int Ornithol Congr, Durban. BirdLife South Africa, Johannesburg, p 2040-2056

Hyrenbach KD, Fernandez P, Anderson DJ (2002) Oceanographic habitats of two sympatric North Pacific albatrosses during their breeding season. Mar Ecol Prog Ser 233: 283-301

IATTC (Inter-American Tropical Tuna Commission) (2006) Fishery status report No. 4, Tunas and billfishes in the Eastern Tropical Pacific in 2005. IATTC, La Jolla, CA
Jaquemet S, Le Corre M, Weimerskirch H (2004) Seabird community structure in a coastal tropical environment: importance of natural factors and fish aggregating devices (FADs). Mar Ecol Prog Ser 268:281-292

Le Corre M, Cherel Y, Lagarde F, Lormée H, Jouventin P (2003) Seasonal and inter-annual variation in the feeding ecology of a tropical oceanic seabird, the red-tailed tropicbird Phaethon rubricauda. Mar Ecol Prog Ser 255: 289-301

Lewis S, Sherratt TN, Hamer KC, Wanless S (2001) Evidence of intra-specific competition for food in a pelagic seabird. Nature 412:816-819

> Lewis S, Schreiber EA, Daunt F, Schenk GA, Wanless S, Hamer KC (2004) Flexible foraging behaviour under different time constraints in tropical boobies. Anim Behav 68: 1331-1337

Longhurst AR, Pauly D (1987) Ecology of tropical oceans. Academic Press, San Diego, CA

Nelson JB (1978) The Sulidae: gannets and boobies. Oxford University Press, Oxford

Nesis KN (1987) Cephalopods of the world. Squids, cuttlefishes, octopuses and allies. T.F.H. Publications, Neptune City, NJ

Nevitt G, Veit RR (1999) Mechanisms of prey-patch detection by foraging seabirds. In: Adams NJ, Slotow RH (eds) Proc 22nd Int Ornithol Congr, Durban. BirdLife South Africa, Johannesburg, p 2072-2082

Pennington JT, Mahoney KL, Kuwahara VS, Kolber DD, Calienes R, Chavez FP (2006) Primary production in the eastern tropical pacific: a review. Prog Oceanogr 69: 285-317

Perrin WF, Wanrner RR, Fiscus CH, Holts DB (1973) Stomach contents of porpoise, Stenella spp., and yellowfin tuna, Thunnus albaceres, in mixed-species aggregations. Fish Bull 71:1077-1092

Phillips RA, Xavier JC, Croxall JP (2003) Effects of satellite transmitters on albatrosses and petrels. Auk 120: 1082-1090

Pinaud D (2008) Quantifying search effort of moving animals at several spatial scales using First-Passage Time analysis: effect of the structure of the environment and of the tracking system. J Appl Ecol 45:91-99

Pitman RL, Ballance LT, Taylor B, Fluty J (in press) The masked boobies (Sula dactylatra) of Clipperton: recovery and status of the world's largest population. Auk

Schneider DC (1993) Scale dependent spatial dynamics: marine birds in the Bering Sea. Biol Rev Camb Philos Soc 68:579-598

Schreiber EA, Schreiber RW, Schenk GA (1996) Red-footed booby (Sula sula). In: Poole A, Gill F (eds) The birds of North America, No 241. The Academy of Natural Sciences, Philadelphia, PA, and The American Ornithologist' Union, Washington, DC

Seaman DE, Powell RA (1996) An evaluation of the accuracy of kernel density estimators for home range analysis. Ecology 77:2075-2085

Smith MM, Heemstra PC (eds) (1986) Smith's sea fishes. Springer-Verlag, New York

Steiner I, Bürgi C, Werffeli S, Dell'Omo G and others (2000) A GPS logger and software for analysis of homing in pigeons and small mammals. Physiol Behav 71:589-596

Veit RR, Prince PA (1997) Individual and population level dispersal of Black-browed and Grey-headed albatrosses in response to Antarctic krill. Ardea 85:129-134

Weimerskirch H (2007) Are seabirds foraging for unpredictable resources? Deep-Sea Res II 54:211-223

Weimerskirch H, Bartle JA, Jouventin P, Stahl JC (1988) For- 
aging ranges and partitioning of feeding zones in the three species of southern albatrosses. Condor 90:214-219

Weimerskirch H, Guionnet T, Martin J, Shaffer SA, Costa DP (2000) Fast and fuel-efficient? Optimal use of wind by flying albatrosses. Proc R Soc Lond B Biol Sci 267:1869-1874

Weimerskirch H, Le Corre M, Jaquemet S, Marsac F (2005) Foraging strategy of a tropical seabird, the red-footed booby, in a dynamic marine environment. Mar Ecol Prog Ser 288:251-261

Weimerskirch H, Le Corre M, Ropert-Coudert Y, Kato A, Marsac F (2006) Sex-specific foraging behaviour in a seabird with reversed sexual dimorphism, the red-footed booby. Oecologia 146:681-691

Weimerskirch H, Pinaud D, Pawlowski F, Bost CA (2007) Does prey capture induce area-restricted search? A fine scale

Editorial responsibility: Otto Kinne,

Oldendorf/Luhe, Germany study using GPS in a marine predator, the wandering albatross. Am Nat 170:734-743

Willett CS, Leben RR, Lavin MF (2006) Eddies and tropical instability waves in the eastern tropical Pacific: a review. Prog Oceanogr 69:218-238

Wolanski E, Hamner WM (1988) Topographically controlled fronts in the ocean and their biological influences. Science 241:177-181

> Wood AG, Naef-Daenzer P, Prince PA, Croxall JP (2000) Quantifying habitat use in satellite tracked pelagic seabirds: application of the kernel estimation to albatross locations. J Avian Biol 31:278-286

- Worton BJ (1995) Using Monte Carlo simulation to evaluate kernel-based home range estimators. J Wildl Manag 59: $794-800$

Submitted: July 18, 2007; Accepted: January 28, 2008

Proofs received from author(s): May 30, 2008 